\title{
A novel bone cement impregnated with silver-tiopronin nanoparticles: its antimicrobial, cytotoxic, and mechanical properties
}

This article was published in the following Dove Press journal:

International Journal of Nanomedicine

17 June 2013

Number of times this article has been viewed

\author{
Polina Prokopovich ${ }^{1,2}$ \\ Ralph Leech ${ }^{3}$ \\ Claire J Carmalt ${ }^{3}$ \\ Ivan P Parkin ${ }^{3}$ \\ Stefano Perni ${ }^{4}$ \\ 'School of Pharmacy and \\ Pharmaceutical Sciences, Cardiff \\ University, Cardiff, UK; ${ }^{2}$ Institute \\ of Medical Engineering and Medical \\ Physics, School of Engineering, Cardiff \\ University, Cardiff, UK; ${ }^{3}$ Materials \\ Chemistry Research Centre, \\ Department of Chemistry, University \\ College London, London, UK; ${ }^{4}$ School \\ of Chemical Engineering, University of \\ Birmingham, Birmingham, UK
}

\begin{abstract}
Post-operatory infections in orthopedic surgeries pose a significant risk. The common approach of using antibiotics, both parenterally or embedded in bone cement (when this is employed during surgery) faces the challenge of the rising population of pathogens exhibiting resistance properties against one or more of these compounds; therefore, novel approaches need to be developed. Silver nanoparticles appear to be an exciting prospect because of their antimicrobial activity and safety at the levels used in medical applications. In this paper, a novel type of silver nanoparticles capped with tiopronin is presented. Two ratios of reagents during synthesis were tested and the effect on the nanoparticles investigated through TEM, TGA, and UV-Vis spectroscopy. Once encapsulated in bone cement, only the nanoparticles with the highest amount of inorganic fraction conferred antimicrobial activity against methicillin resistant Staphylococcus aureus (MRSA) at concentrations as low as $0.1 \% \mathrm{w} / \mathrm{w}$. No other characteristics of the bone cement, such as cytotoxicity or mechanical properties, were affected by the presence of the nanoparticles. Our work presents a new type of silver nanoparticles and demonstrates that they can be embedded in bone cement to prevent infections once the synthetic conditions are tailored for such applications.
\end{abstract}

Keywords: bone cement, antimicrobial, silver nanoparticles, tiopronin, MRSA

\section{Introduction}

Bone cement is employed in orthopedic surgeries to join fractured bones or to fix devices in place in dentistry and arthroplasty. This kind of surgery constitutes the replacement of a damaged body part (either by a degenerative disease or by an acute injury) with an artificial one; the common types of operations are hip, knees, and spine disk replacement. In 2005, 1.3 million people underwent knee arthroplasty, total and partial hip replacement, and spinal fusion in the US, ${ }^{1}$ whilst 65,229 primary hip and 72,980 primary knee replacement procedures were performed in England and Wales in 2009. ${ }^{2}$ It is expected that these operations will be performed on an increasing number of patients because of the improvement in life quality and the constantly aging population. ${ }^{3,4}$ The downside of these operations is the risk for the patient of developing a deep wound infection; it is estimated that such infections have an incidence of about $1 \%-9 \%$ depending on the type of surgery. ${ }^{5}$ Furthermore, infections are $40 \%$ more likely from revision surgery than from the first implantation. ${ }^{6}$ Besides the cost associated with the prolonged hospital stay (on average, $\$ 15,000-\$ 30,000$ for an estimated 14 days), ${ }^{7}$ the onset of infection has a potentially debilitating and life threatening impact on patients. In order to reduce the chances of post-operatory infection occurrence at surgical sites, various approaches have been attempted. Prophylactic parenteral antibiotics therapy ${ }^{8-10}$ and antibiotic-releasing bone cement ${ }^{11-16}$ have been successful; however, the use of
Correspondence: Polina Prokopovich School of Pharmacy and Pharmaceutical Sciences, Cardiff University,

Cardiff, CFIO 3NB, UK

$\mathrm{Tel}+4402920875820$

Fax +44 02920874149

Email prokopovichp@cf.ac.uk 
antibiotics has given rise to bacterial strains resistant to such compounds. ${ }^{17}$ Therefore, reliance on antibiotics cannot be seen as a long-term approach and the development of nonantibiotic antimicrobial techniques is extremely urgent.

The applications of photodynamic therapy ${ }^{18-20}$ and cold gas plasma ${ }^{21-23}$ have seen a lot of growing interest in areas such as surface cleaning and catheters, as their multi-target lethality mechanism of action is unlikely to induce the development of resistance. ${ }^{24}$ Another antimicrobial approach that has shown significant potential is the use of metals, mainly silver. ${ }^{25}$ Silver ions have been added to bone cement demonstrating antibacterial action without impinging on the cytotoxicity of the biomaterial. ${ }^{26,27}$ Silver nanoparticles, sometimes called colloidal silver or metal silver, have also proved an effective antimicrobial agent and they have been encapsulated in many medical devices to confer these antimicrobial properties to bandages, ${ }^{28}$ sutures, ${ }^{29}$ surgical scrubs, ${ }^{30}$ and catheters. ${ }^{31}$ Many different synthetic routes have been proposed to prepare silver nanoparticles; in general, ionic silver $\left(\mathrm{Ag}^{+}\right)$contained in a salt, generally $\mathrm{AgNO}_{3}$, is reduced to metal silver $\left(\mathrm{Ag}^{0}\right)$ through a reducing agent such as $\mathrm{HNO}_{3} /$ citrate, ${ }^{32}$ Al-alkoxide, ${ }^{33} \mathrm{NaBH}_{4},{ }^{34} \mathrm{~N}, \mathrm{~N}$-dimethyl formamide, ${ }^{35}$ or sugars. ${ }^{36,37}$ The nanoparticles can also be stabilized using chelating substances such as citrates, ${ }^{38}$ oleic acid, ${ }^{37}$ and glutamic acid ${ }^{39}$ or prepared with a capping agent that allows binding of other compounds to the nanoparticles; for example, glutathione ${ }^{40}$ or tiopronin. ${ }^{41}$ Silver nanoparticles of very different geometric (size and shape) characteristics can be obtained by modifying the reaction conditions. ${ }^{42}$ It is recognized that the preparation method influences the interactions of the silver nanoparticles with living organisms; therefore, the nanoparticles can be tuned to the required application through controlling the synthetic conditions.

In this work, a new synthetic route for the preparation of silver nanoparticles is presented resulting in a novel type of nanoparticles with very controlled geometrical properties and stability; the synthetic conditions were optimized to obtain the highest antimicrobial activity once the nanoparticles were embedded in the bone cement. Silver nanoparticles capped with tiopronin were synthesized in different conditions and variations of the nanoparticles size and of the amount of capping agent determined. The antimicrobial activity of bone cement containing the prepared nanoparticles in various ratios was then assessed against methicillin resistant Staphylococcus aureus (MRSA), revealing that the larger nanoparticles with a higher amount of silver were more effective than the smaller ones which had greater proportions of tiopronin. No effect on the mechanical and cytotoxic properties of the bone cement was caused by the embedded nanoparticles. Furthermore, silver ion release from the bone cement containing nanoparticles proved that the antimicrobial activity mechanism of these silver nanoparticles is not completely through the discharge of ions in the surrounding fluid.

\section{Materials and methods \\ Silver-tiopronin nanoparticles preparation and characterization} Chemicals

$\mathrm{AgNO}_{3}$ ( $\left.\geq 99.0 \%\right)$, N-(2-mercaptopropionyl)glycine (tiopronin, 99\%), and sodium borohydride (99\%) were supplied by Sigma Aldrich (St Louis, MO, USA). Buffer solutions were prepared according to standard laboratory procedure. All other chemicals were reagent grade and used as received.

\section{Synthesis of particles}

Silver nitrate $(0.5091 \mathrm{~g}, 3 \mathrm{mmol})$ and tiopronin $(1.4231 \mathrm{~g}$, $8.70 \mathrm{mmol}$ ) were dissolved in water $(25 \mathrm{~mL}$ and $10 \mathrm{~mL}$, respectively) and combined to give a cloudy yellow-white solution. This mixture was cooled to $0^{\circ} \mathrm{C}$ before sodium borohydride $(0.3301 \mathrm{~g}, 8.72 \mathrm{mmol})$ in water $(10 \mathrm{~mL})$ was added over 2 minutes with vigorous stirring. The overall mole ratio of $\mathrm{AgNO}_{3}$ :tiopronin: $\mathrm{NaBH}_{4}$ was 1:3:3. Stirring was continued for 1 hour, in which time the solution cleared and became a very dark red-brown. Methanol $(100 \mathrm{~mL})$ was added to precipitate the particles which were isolated by centrifuge (15 minutes at $4000 \mathrm{rpm}$ ) and the colorless supernatant removed. The pellet was re-dispersed in methanol $(40 \mathrm{~mL})$ and centrifuged out twice to wash it before dispersing in acetone $(40 \mathrm{~mL})$. Tiopronin-coated silver nanoparticles were isolated on an FHLC membrane filter (pore size $0.45 \mu \mathrm{m}$ ), before being dried on a watch glass.

To produce silver nanoparticles of a different size, the same procedure was followed using silver nitrate $(0.5021 \mathrm{~g}$, $2.96 \mathrm{mmol})$, tiopronin $(0.2513 \mathrm{~g}, 1.54 \mathrm{mmol})$, and sodium borohydride $(0.3349 \mathrm{~g}, 8.85 \mathrm{mmol})$. This gave a mole ratio of $1: 0.5: 3$.

\section{UV}

UV-vis spectra (250-800 $\mathrm{nm}, 1 \mathrm{~nm}$ resolution) were recorded in $1 \mathrm{~cm}$ quartz cells with a ThermoSpectronic, Helios- $\lambda$ UV-vis spectrophotometer (Thermo Scientific, Swedesboro, NJ, USA). Infrared spectra were collected of samples pressed into a $\mathrm{KBr}$ plate. These were recorded from 3800 to $500 \mathrm{~cm}^{-1}$ with a Shimadzu 8700 FT-IR spectrometer (Kyoto, Japan). 


\section{Thermogravimetric analysis (TGA)}

TGA was performed using a Netzsch STA 449C TGA system (Selb, Germany). Data was recorded from $25^{\circ} \mathrm{C}$ to $1000^{\circ} \mathrm{C}$ with a constant heating rate of $10^{\circ} \mathrm{C}$ per minute.

\section{Element analysis}

Elemental analyses were obtained using an Elemental Analyser CE-440 (Exeter Analytical Inc, North Chelmsford, MA, USA).

\section{Transmission electron microscopy (TEM) - size distribution}

For TEM characterization, a $4 \mu \mathrm{L}$ droplet of nanoparticles suspension was placed on a plain carbon-coated copper TEM grid and allowed to evaporate in air under ambient laboratory conditions for several hours. Bright field TEM images were obtained using a JEOL-1010 microscope (Tokyo, Japan) at $80 \mathrm{kV}$ equipped with a Gatan digital camera (Pleasanton, CA, USA). Typical magnification of the images was at 100,000 $\times$. Images were analyzed with the computer program ImageJ (National Institutes of Health, Bethesda, MD, USA) and the diameters of at least 150 particles for each synthetic condition were determined.

\section{Bone cement preparation and characterization}

The silver-tiopronin nanoparticles were mixed with polymethyl methacrylate (PMMA) based bone cement at various ratios to achieve $1,0.5$, and $0.1 \%(\mathrm{w} / \mathrm{w})$ silver concentration in the cement. The cement was prepared by manually mixing the powder with the liquid monomer under constant stirring until the powder was fully wetted. The mixture was subsequently inserted into the mould at an approximate dough time of 1 minute. The filled mould was pressed between two glass plates for 1 hour. After the cement had hardened, it was pulled out from the mould and stored under dark, sterile conditions at room temperature. All assays were performed on cylindrical specimens $(6 \mathrm{~mm}$ in diameter and $12 \mathrm{~mm}$ in height). Prior to all testing bone cement specimens were conditioned at $37^{\circ} \mathrm{C}$ for 24 hours.

\section{Testing of mechanical properties of bone cement}

Compression tests were undertaken on the Zwick Roell ProLine table-top Z050/Z100 materials testing machine according to BS ISO 5833:2002 (Ulm, Germany). The compression tests were conducted at a constant cross-head speed of $20.0 \mathrm{~mm} / \mathrm{min}$ to produce a curve of displacement against load. For each specimen, the compressive strength of the bone cement was determined by dividing the force applied to cause fracture by the original cross-sectional area of the cylinder. The average compressive strength of five cylinders has been calculated.

\section{Determination of antimicrobial activity of bone cement}

The antimicrobial activity of the bone cement samples was tested using the Gram-positive bacteria MRSA (strain NCIMB 9518). The method has been adopted from Bechert et al. ${ }^{43}$ The microorganisms were cultured in brain heart infusion (BHI) broth at $37^{\circ} \mathrm{C}$ for 24 hours. Bone cement samples with different concentrations of silver-tiopronin nanoparticles were placed into 24-well plates. The experiment was performed in duplicate on three independent cultures (six in total).

Microorganisms suspension $(2.5 \mathrm{~mL})$ was added to each well to cover the bone cement sample and incubated at $37^{\circ} \mathrm{C}$ for 1 hour to allow microorganisms to adhere to the cement. After 1 hour, the microbial suspension was removed and the cement was rinsed three times with PBS. Five hundred microliters of 1/10 BHI (dilution with PBS) were added in each well and the plate was incubated at $37^{\circ} \mathrm{C}$ for 24 hours. During this phase, the microorganisms adhering to the cement were detached. From each well, $50 \mu \mathrm{L}$ of the PBS was transferred in another 100-well plate where each well contained $100 \mu \mathrm{L}$ of fresh BHI broth. This plate was then incubated in a plate reader (Bioscreen C analyzer; Labsystems, Helsinki, Finland) at $37^{\circ} \mathrm{C}$ and the growth curves in each plate were recorded by measuring optical density at $600 \mathrm{~nm}\left(\mathrm{OD}_{600}\right)$ for 24 hours. The microbial growth curves were fitted with the Baranyi-Roberts model, which is shown in Equation 1, using SigmaPlot in order to estimate the duration of the lag phase $(\lambda)$ and the maximum growth rate $\left(\mu_{\max }\right)$.

$$
y(t)=y_{0}+\mu_{\max } A(t)-\ln \left(1+\frac{e^{\mu_{\max } A(t)}-1}{e^{\left(y_{\max }-y_{0}\right)}}\right)
$$

where

$$
A(t)=t+\frac{1}{\mu_{\max }} \ln \left(e^{-\mu_{\max } t}+e^{-h_{0}}-e^{-\mu_{\max } t-h_{0}}\right)
$$

and

$$
h_{0}=\mu_{\max } \lambda
$$

\section{Distribution of nanoparticles in bone cement}

Ultrathin sections were cut on a LKB III Ultramicrotome (Paris, France). For trimming the bone cement samples, glass 
knives were used to form the classic pyramid shape with a flat top, which is termed the 'block face', and is shiny in appearance. Ultrathin sections of $90 \mathrm{~nm}$ thickness were cut from the 'block face' using a diamond knife and picked up on to 200-mesh gold grids with a carbon film (S160A; Agar Scientific, Stansted, UK) and air dried.

Sections were viewed using TEM (Philips CM12; FEI Ltd, Hillsboro, OR, USA) operating at $80 \mathrm{kV}$ fitted with an X-ray microanalysis detector (EM-400 Detecting Unit; EDAX UK, Leicester, UK) utilizing EDAX's Genesis software. Images were recorded using a SIS MegaView III digital camera (SIS Analytical, Germany) at different radial positions (center, middle, and close to the outer surface) of bone cement samples.

\section{In vitro cytotoxicity studies of bone cement}

Osteoblast cells (MC 3TC) were cultured in Dulbecco's Modified Eagle's Medium supplemented with fetal bovine serum $(10 \% \mathrm{v} / \mathrm{v})$; cells were incubated at $37^{\circ} \mathrm{C}$ in a humidified atmosphere with $5 \% \mathrm{CO}_{2}$. Cells were grown till confluence, washed twice with sterile PBS, and detached with trypsine; osteoblast cells were counted (using trypan blue to differentiate between viable and non-viable cells) and diluted to a concentration $10^{5}$ cells $/ \mathrm{mL}$ with fresh medium.

Bone cement samples were sterilized with $70 \%$ alcohol and washed three times with sterile PBS prior to use. Samples were placed in 24-well plates containing $2 \mathrm{~mL}$ of osteoblast cells suspension prepared as described above. Osteoblasts were incubated with the bone cement at $37^{\circ} \mathrm{C}$ in a humidified atmosphere with $5 \% \mathrm{CO}_{2}$.

After 2 days, the bone cement samples were transferred to a clean 24-well plate with $2 \mathrm{~mL}$ of fresh medium without red phenol. Osteoblast cell viability was assessed using the MTT assay kit (Invitrogen, Paisley, UK). The MTT solution was prepared according to the manufacturer guidelines and $10 \mu \mathrm{L}$ added to each well. After incubation for 2 hours at $37^{\circ} \mathrm{C}$ in a humidified atmosphere with $5 \% \mathrm{CO}_{2}$, the samples were transferred in a new 24-well plate and the MTT solubilization solution added; when full dissolution of the crystals occurred, $100 \mathrm{~mL}$ of liquid was transferred to a 96-well plate where the absorbance of each sample was read at $570 \mathrm{~nm}$. Results are presented as the mean and standard deviation of three independent bone cement samples.

\section{Silver release studies from bone cement}

The silver ion release from set bone cement samples was determined by inductively coupled plasma-mass spectroscopy (ICP-MS) analysis (Optima 2100DV OES;
Perkin Elmer, Waltham, MA, USA) against the Primar 28 element standard, which had silver at a concentration of $100 \mathrm{mg} / \mathrm{L}$ from which subsequent dilutions were made. Prior to testing, three samples of bone cement were placed in $10 \mathrm{~mL}$ of fresh sterile PBS (137 mM NaCl, $2.7 \mathrm{mM} \mathrm{KCl}$, $7.0 \mathrm{mM} \mathrm{Na} \mathrm{HPO}_{4} \times 2 \mathrm{H}_{2} \mathrm{O}, 1.5 \mathrm{mM} \mathrm{KH}_{2} \mathrm{PO}_{4}$ ) and were kept at $37^{\circ} \mathrm{C}$ for 7 days with a daily change of immersion liquid. Silver ion release was measured daily.

\section{Statistical analyses}

ANOVA and $t$-tests were performed on the results using SPSS (v12.0; SPSS Inc, Chicago, IL, USA). For all analyses, $P<0.05$ was considered statistically significant.

\section{Results}

The UV-Vis spectra of the solutions containing the synthesized nanoparticles are shown in Figure 1; both solutions showed an adsorption characteristic of a surface plasmon resonance. Particles synthesized from a $\mathrm{AgNO}_{3}$ :tiopronin ratio of 1:3 exhibited an adsorption peak at about $380 \mathrm{~nm}$ and those produced from a reactant ratio of 1:0.5 adsorbed at $400 \mathrm{~nm}$. The composition of the nanoparticles was investigated through element analysis (Table 1). These results show that the synthesis conditions have a significant effect on the amount of tiopronin capped to the nanoparticles. Silvertiopronin nanoparticles produced with a $\mathrm{AgNO}_{3}$ :tiopronin ratio of 1:0.5 return the highest amount $(80.6 \% \mathrm{w} / \mathrm{w})$ of $\mathrm{Ag}$ in the nanoparticles, whilst those synthesized with a ratio of 1:3 return an Ag amount of $44.8 \%$ w/w. TGA (Figure 2) confirmed this as the mass reduction of the two samples at about $300^{\circ} \mathrm{C}$ was $10 \%$ and $25 \%$, respectively.

Examples of TEM images of the two types of nanoparticles are shown in Figure 3. All particles appeared rounded; the

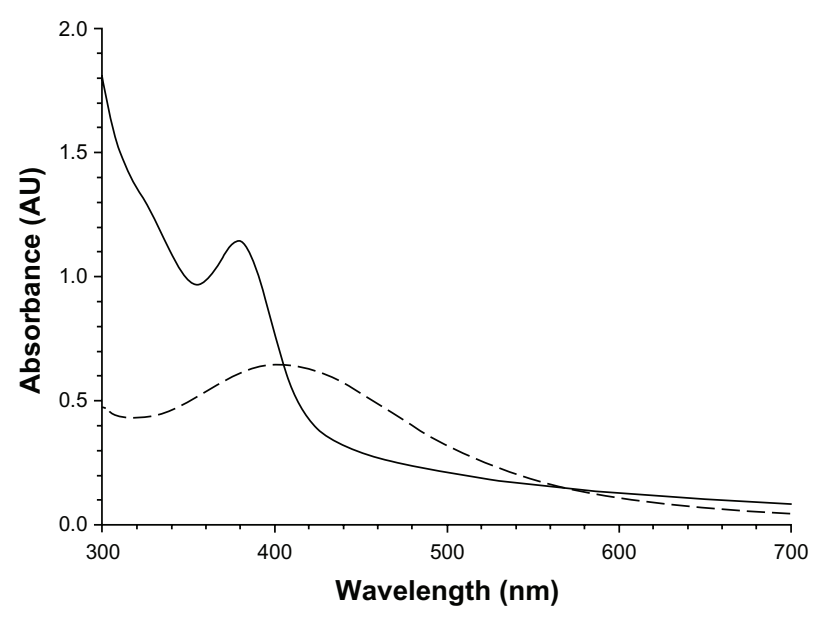

Figure I UV-Vis spectra of the solutions containing the two sets of nanoparticles. Notes: _ _ _ _ _ I:0.5 $\mathrm{AgNO}_{3}$ :Tiopronin; __ I:3 $\mathrm{AgNO}_{3}:$ Tiopronin. 
Table I Ratios of organic/inorganic composition of the $\mathrm{Ag}$ tiopronin capped nanoparticles

\begin{tabular}{lll}
\hline $\mathbf{A g N O}_{3}:$ Tiopronin & $\% \mathbf{A g}$ & \% organic \\
\hline I:3 & 44.8 & 55.2 \\
I:0.5 & 80.6 & 19.4 \\
\hline
\end{tabular}

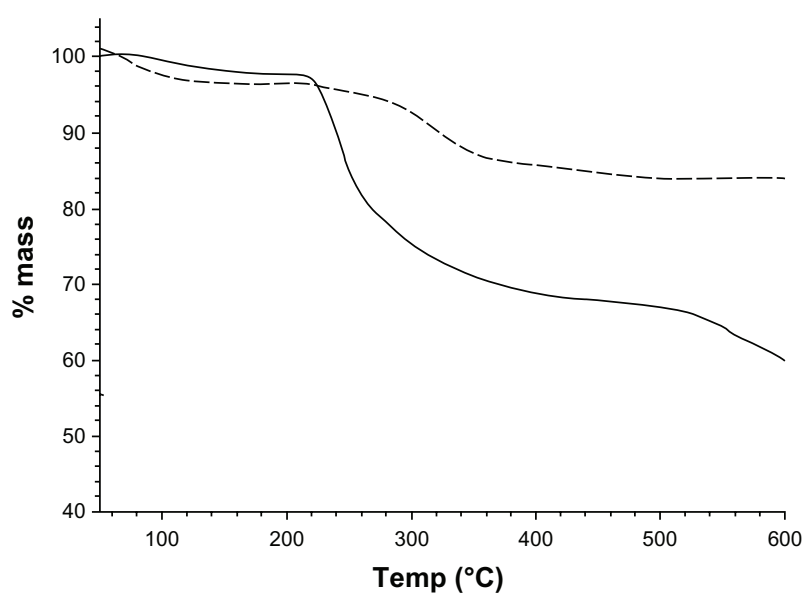

Figure 2 Thermal gravimetric analysis of the two sets of nanoparticles. Notes: _.__ _ 1:0.5 $\mathrm{AgNO}_{3}:$ Tiopronin; __ 1:3 $\mathrm{AgNO}_{3}$ :Tiopronin.
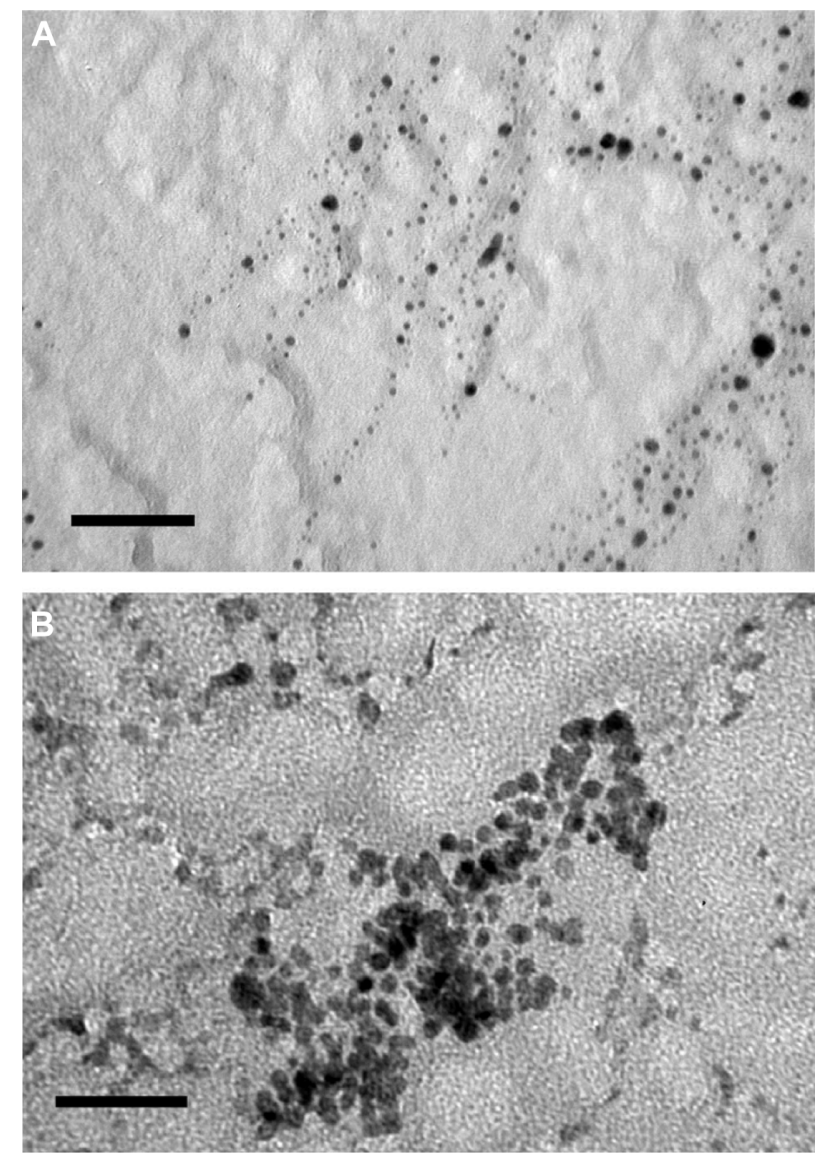

Figure 3 TEM images of nanoparticles. (A) 1:3 $\mathrm{AgNO}_{3}:$ Tiopronin; (B) 1:0.5 $\mathrm{AgNO}_{3}$ :Tiopronin.

Note: $B$ ar is equal to $50 \mu \mathrm{m}$. cumulative distributions of the nanoparticles diameters are presented in Figure 4; these distributions are closely modeled by a normal distribution. The nanoparticles synthesized with a larger quantity of tiopronin had a mean diameter of $5.3 \pm 2.2 \mathrm{~nm}$; whilst the nanoparticles synthesized with a lower tiopronin to silver ratio had a mean diameter of $11.4 \pm 4.3 \mathrm{~nm}$. The difference in diameter was statistically significant $(P<0.05)$. When dispersed in bone cement, the nanoparticles of both types did not aggregate and they were uniformly distributed in the sample as TEM images taken at different positions along a radius showed similar amounts of nanoparticles (Figure 5).

The antimicrobial properties of the bone cements embedded with the Ag nanoparticles were determined through the lag phase and growth rate of the MRSA cells detached from the bone cement samples. Examples of these curves are shown in Figure 6. For the samples (control) without nanoparticles, the $\mathrm{OD}_{600}$ of the solution starts increasing after about 1-2 hours and decelerates after 4 hours; the OD
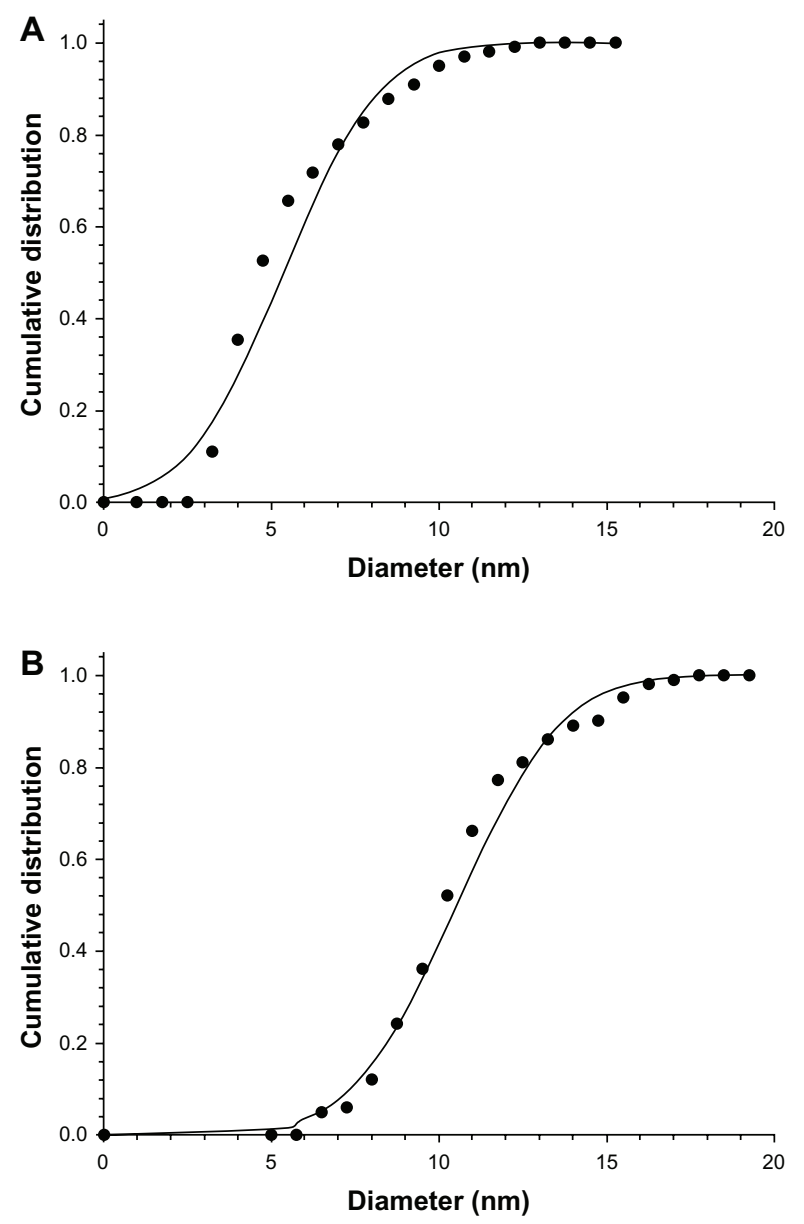

Figure 4 Cumulative distributions of nanoparticles diameters. (A) I:3 $\mathrm{AgNO}_{3}$ : Tiopronin; (B) I:0.5 $\mathrm{AgNO}_{3}$ :Tiopronin.

Note: Solid points are experimental data and continuous line is Gaussian fitting. 

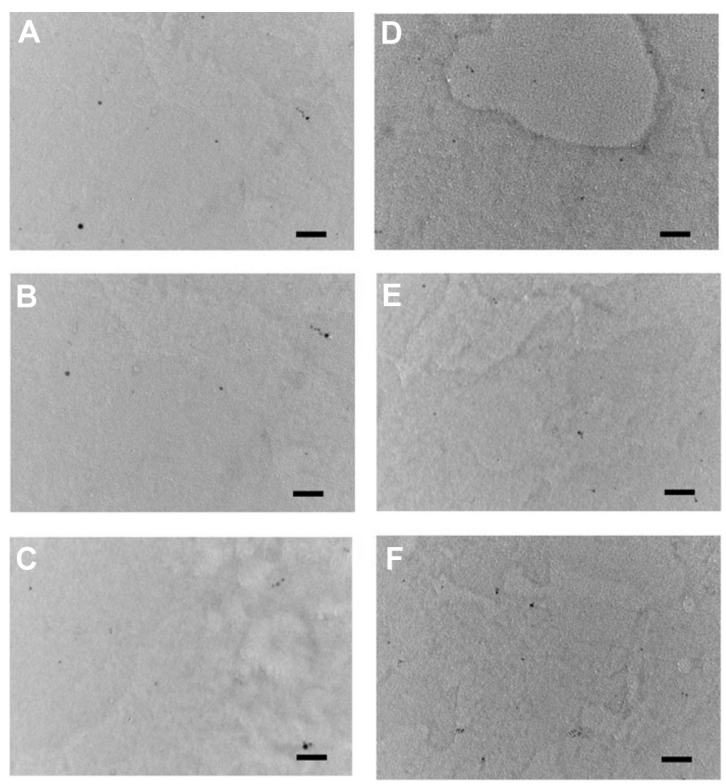

Figure 5 TEM images of bone cement containing I\% Ag nanoparticles of $5 \mathrm{~nm}$ $\left(\mathrm{AgNO}_{3}\right.$ :Tiopronin $\left.\mathrm{I:3}\right)$ in the center of the cylinder sample (A); between center and outer surface (B); on the outer surface $(\mathbf{C})$; of II nm nanoparticles $\left(\mathrm{AgNO}_{3}\right.$ :Tiopronin I:0.5) in the center of the cylinder sample (D); between center and outer surface $(\mathbf{E})$; and on the outer surface $(\mathbf{F})$.

Note: Bar is equal to $50 \mathrm{~nm}$.
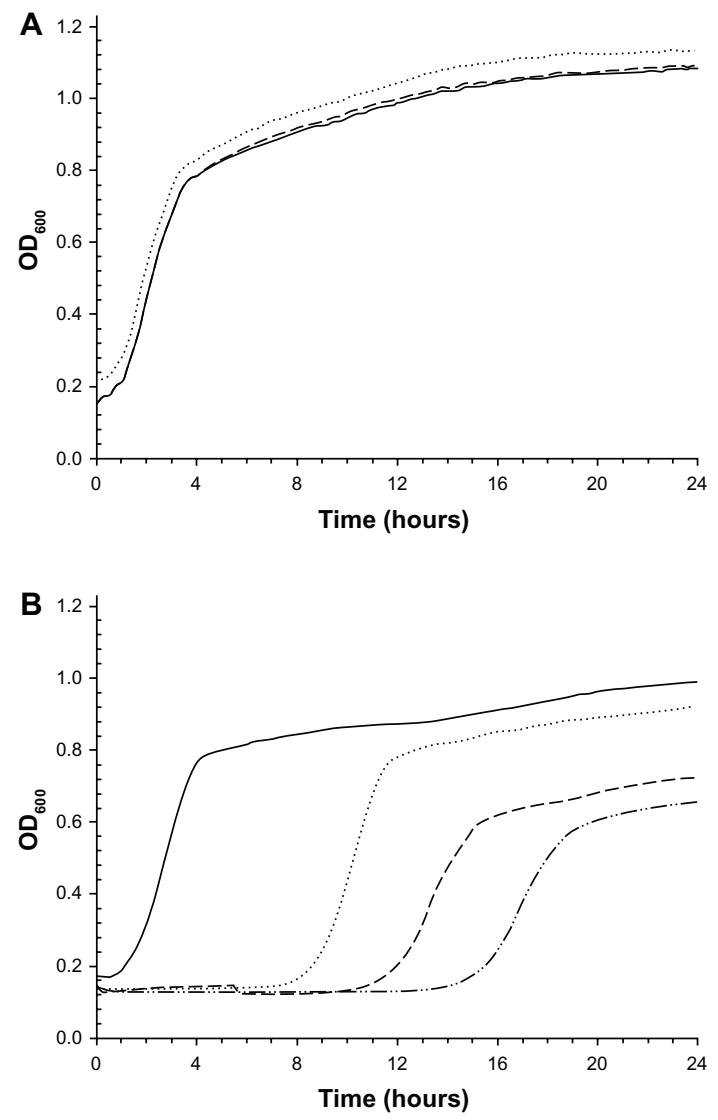

Figure 6 Examples of growth curve of MRSA survivors on bone cement containing (A) $5 \mathrm{~nm}\left(\mathrm{AgNO}_{3}\right.$ :Tiopronin I:3) and (B) II nm Ag nanoparticles $\left(\mathrm{AgNO}_{3}:\right.$ Tiopronin I:0.5) in different amounts $(w / w)$.

Notes: $0 \%$; ................ $0.1 \%$; _

Abbreviations: OD, optical density; MRSA, methicillin resistant Staphylococcus aureus. continues to increase until 24 hours. Samples containing the $5.3 \mathrm{~nm}$ nanoparticles returned the same profile of growth curve as the controls, meaning that no antimicrobial effect was caused by these nanoparticles irrespective of the concentration used. The growth curve related to the samples containing the $11.4 \mathrm{~nm}$ nanoparticles showed a lag phase longer than the lag phase of the control samples. The higher the concentration of this type of nanoparticles, the longer the lag phase (Table 2). The control returned a log phase of 2.4 hours whilst the sample with $1 \% \mathrm{Ag}$ nanoparticles $(10 \mathrm{~nm})$ had a lag phase of 16.4 hours; the addition of $0.1 \%$ of nanoparticles gave a lag phase of 9.2 hours. All these differences are statistically significant $(P<0.05)$. The growth rate of the samples was $1.5 \mathrm{~h}^{-1}$ irrespective of the concentration and type of Ag nanoparticles (Table 2).

The possibility of Ag nanoparticles having a cytotoxic effect was investigated through the MTT assay on osteoblast cells (Figure 7). The presence of Ag nanoparticles capped with tiopronin did not impact on the outcome of the enzymatic activity tested by the MTT $(P>0.05)$ as all samples returned an $\mathrm{OD}$ reading at $540 \mathrm{~nm}$ of the solution containing the dissolved formazan produced of about 0.4 au.

The mechanical properties of the bone cement with $\mathrm{Ag}$ nanoparticles embedded were assessed through the compression strength (Figure 8). Bone cement without any nanoparticles had a compression strength of $98 \pm 5 \mathrm{MPa}$, whilst the presence of these nanoparticles did not have a significant impact of the resistance to compression compared to control samples without nanoparticles $(P>0.05)$.

The bone cement loaded with Ag nanoparticles continuously released $\mathrm{Ag}^{+}$ions to the surrounding liquid (Figure 9). The cumulative amount of $\mathrm{Ag}^{+}$ions increased monotonically from day 1 to day 7 for all samples; the amount of increase after each day diminished with increasing time, with curves tending to reach a plateau. One percent

Table 2 Lag phase and growth rate of the growth curves of MRSA survival in bone cement containing Ag nanoparticles capped with tiopronin

\begin{tabular}{lll}
\hline $\begin{array}{l}\text { Concentration of } \mathbf{A g} \\
\text { nanoparticles }\end{array}$ & $\boldsymbol{\lambda}(\mathbf{h})$ & $\begin{array}{l}\text { Growth rate } \\
\left(\mathbf{h}^{-1}\right)\end{array}$ \\
\hline $0 \%$ & $2.5 \pm 0.3$ & $1.5 \pm 0.2$ \\
$0.1 \%, 5 \mathrm{~nm}$ & $2.4 \pm 0.3$ & $1.6 \pm 0.3$ \\
$0.5 \%, 5 \mathrm{~nm}$ & $2.5 \pm 0.4$ & $1.5 \pm 0.2$ \\
$1 \%, 5 \mathrm{~nm}$ & $2.4 \pm 0.4$ & $1.4 \pm 0.3$ \\
$0.1 \%, \mathrm{II} \mathrm{nm}$ & $9.2 \pm 0.5$ & $1.5 \pm 0.3$ \\
$0.5 \%, \mathrm{II} \mathrm{nm}$ & $11.8 \pm 0.6$ & $1.3 \pm 0.4$ \\
$1 \%, \mathrm{II} \mathrm{nm}$ & $16.4 \pm 1.0$ & $1.5 \pm 0.3$ \\
\hline
\end{tabular}

Note: Average \pm standard deviation.

Abbreviation: MRSA, methicillin resistant Staphylococcus aureus. 


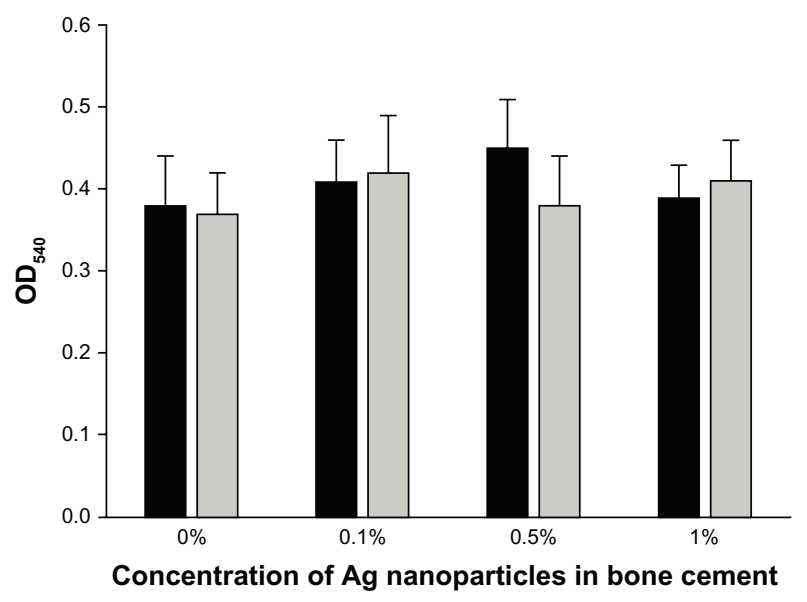

Figure 7 MTT assay for bone cement containing $5 \mathrm{~nm}$ Ag nanoparticles. Notes: $\left(\mathrm{AgNO}_{3}:\right.$ Tiopronin $\left.\mathrm{I}: 3\right) \mathbf{\square}$ and $\mathrm{II} \mathrm{nm} \mathrm{Ag}$ nanoparticles $\left(\mathrm{AgNO}_{3}\right.$ : Tiopronin 1:0.5) ‥

of Ag nanoparticles gave the highest quantity of $\mathrm{Ag}$ in the liquid at about $700 \mu \mathrm{g}$ for both types of nanoparticles; while the smallest amount of $\mathrm{Ag}$ nanoparticles $(0.1 \%)$ gave the lowest release of $\mathrm{Ag}^{+}$ions, $45 \mu \mathrm{g}$ for the larger nanoparticles and $75 \mu \mathrm{g}$ for the smaller nanoparticles. When $0.5 \%$ of nanoparticles was embedded in the bone cement, the total amount of $\mathrm{Ag}^{+}$ions in the immersion liquid was $500 \mu \mathrm{g}$ for the nanoparticles with a diameter of $11.4 \mathrm{~nm}$ and $120 \mu \mathrm{g}$ for the nanoparticles with a diameter of $5.3 \mathrm{~nm}$.

\section{Discussion}

In order to access silver nanoparticles in the sub- $100 \mathrm{~nm}$ size range with sufficient stability to have practical applications, it is essential to stabilize the particles to prevent uncontrolled growth.

This is achieved by coating the surface of the particles with organic molecules or polymers, reducing the surface

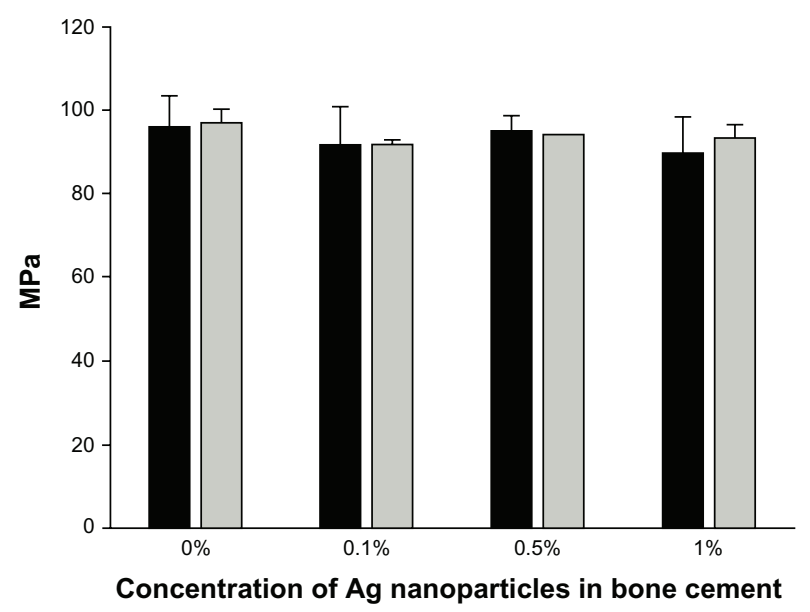

Figure 8 Compression strength of bone cement containing $5 \mathrm{~nm} \mathrm{Ag}$ nanoparticles. Notes: $\left(\mathrm{AgNO}_{3}:\right.$ Tiopronin $\left.\mathrm{I}: 3\right) \mathbf{m}$ and $\mathrm{Il} \mathrm{nm} \mathrm{Ag}$ nanoparticles $\left(\mathrm{AgNO}_{3}\right.$ : Tiopronin $1: 0.5)$.
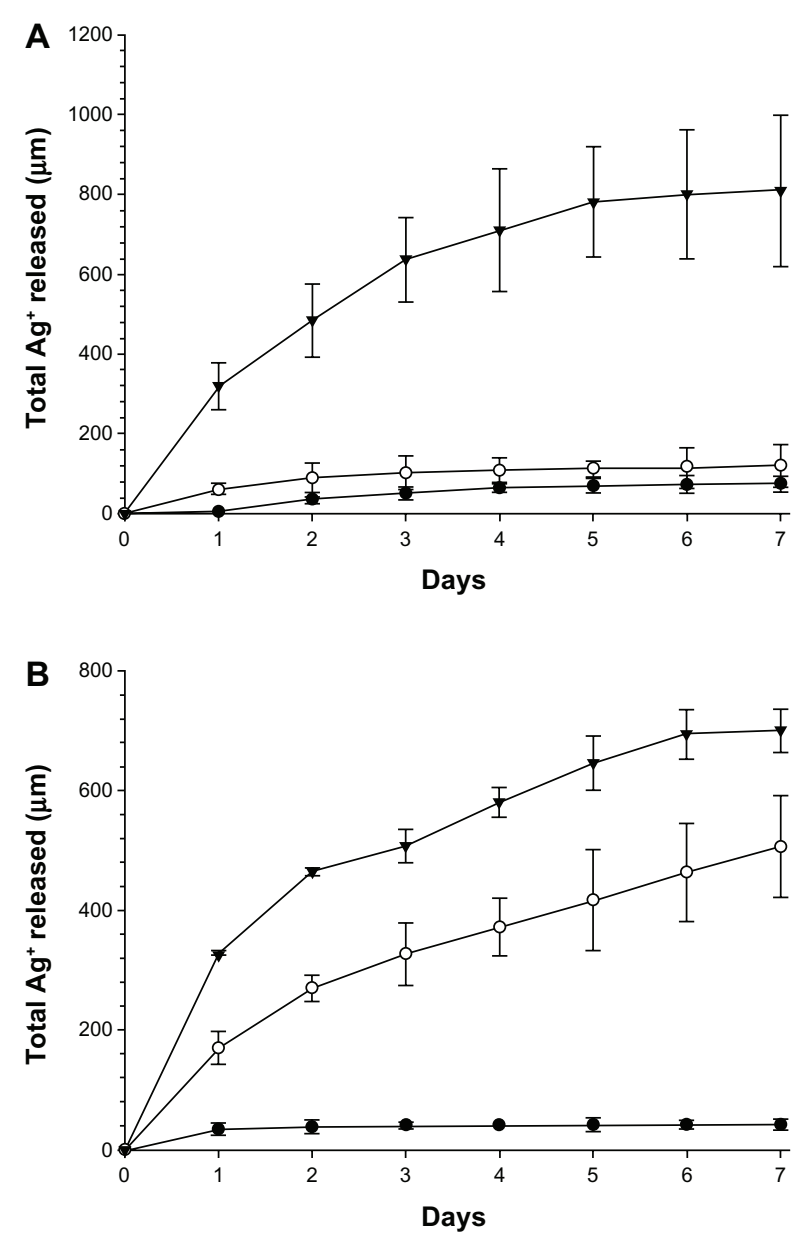

Figure $9 \mathrm{Ag}^{+}$cumulative releases from bone cement containing (A) $5 \mathrm{~nm}$ $\mathrm{Ag}$ nanoparticles ( $\mathrm{AgNO}_{3}:$ Tiopronin $\mathrm{I}: 3$ ) and (B) II nm $\mathrm{Ag}$ nanoparticles ( $\mathrm{AgNO}_{3}$ :Tiopronin I:0.5).

Notes: $0.1 \%$; $\bigcirc .5 \%$; $\nabla$.

energy and increasing particle separation to prevent agglomeration. The size of the particles, their stability, and their solubility are governed by this capping layer. The molecules used must be selected based on the intended applications of the nanoparticles. In this work, tiopronin was chosen as a capping agent for the silver nanoparticles. It was selected due to the exceptional stability of the particles and their solubility in aqueous solutions, making them compatible with biological systems. ${ }^{44}$ Initially used to stabilize gold nanoparticles, the synthesis has been adapted to produce silver nanoparticles with the same stability and solubility. ${ }^{45}$ This stability results from the strong interactions (particularly hydrogen bonds) between the ligands in the capping layer and allows the nanoparticles to be isolated and re-dispersed without agglomeration. It is this re-dispersion from a solid that makes the silver-tiopronin particles suitable for incorporation into bone cement. Two size distributions of silver nanoparticles were produced, with mean diameters 
of $5 \mathrm{~nm}$ and $11 \mathrm{~nm}$, respectively. The mean size of the nanoparticles was controlled thermodynamically by varying the ratio of silver nitrate to tiopronin. ${ }^{46}$ Increasing the amount of capping thiol in the system improves the reduction of the surface energy of the particles through the formation of $\mathrm{Ag}-\mathrm{S}$ bonds, stabilizing their ripening at a smaller diameter. It should be noted that analysis of the $5 \mathrm{~nm}$ particles suggests the presence of tiopronin in the system with a greater than monolayer coverage. The additional tiopronin provides further stabilization of the particles by attaching to the outside of the particle non-covalently to produce multi-layer stabilization. ${ }^{47}$ Tiopronin alone is not known to result in any antimicrobial action; hence, any effect against bacteria cells is due to the silver nanoparticles rather than tiopronin.

The nanoparticles, once encapsulated in bone cement, did not agglomerate and were uniformly distributed throughout the samples (Figure 5); it is, therefore, foreseeable that the behavior detected in the in vitro experiments could be replicated in vivo, as the results are not due to the particular distribution of the nanoparticles in the tested specimens. This could have been the case if, for example, nanoparticles were found predominantly on the outer surface of the samples.

The antimicrobial activity of the bone cement containing the nanoparticles developed was determined by measuring the concentration of the bacterial cell survivors on the bone cements through the duration of the 'lag phase' of their growth curves. The lag phase is the time between the inoculation of a medium and the beginning of the cell concentration increase; its value does not depend on the initial cell concentration. However, when optical density is employed as an indication of cell concentration, the lag phase duration is dependent on the initial value of cell load because the relationship between optical density and cell concentration presents a threshold below which the concentration is not detectable; ${ }^{48}$ the values of lag phase measured in this way are more correctly referred to as 'apparent' lag phase. In our work, this phenomenon is utilized and the lower the amount of living cells attached to the cement, the longer the apparent lag phase, because the number of cell multiplications needed to reach the lower detection limit of optical density is greater. In case no viable cells are present on the material, the lag phase would be infinite.

Our results (Table 2) show that Ag nanoparticles capped with tiopronin are capable of conferring antimicrobial activity to bone cement depending on the synthetic conditions in which they were prepared. The nanoparticles obtained using the lower ratio $\mathrm{AgNO}_{3}$ :tiopronin 1:0.5 were effective at concentrations as low as $0.1 \% \mathrm{w} / \mathrm{w}$; furthermore, the apparent lag phase increases with increasing amount of $\mathrm{Ag}$ nanoparticles. Therefore, the antimicrobial effect is dependent on the concentration of $\mathrm{Ag}$ nanoparticles. In contrast, the nanoparticles synthesized with the higher amount of tiopronin (1:3) did not show any activity even at the highest concentration tested (1\%).

The antimicrobial activity seems dependent on the amount of Ag in the nanoparticles; the smaller nanoparticles have a lower percentage of Ag and are less antimicrobial. Possibly, the higher amount of organic components on the nanoparticles reduces the exposure of the inorganic $(\mathrm{Ag})$ part to the cells or prevents the Ag from interacting with cell components, such as enzymes. The variation in activity could also be caused by the different mean diameter of the nanoparticles synthesized (Figure 4) or by the different percentage of silver in the two types of nanoparticles (Table 1). However, it is also likely that a combination of the two factors is the cause of our results; this hypothesis could not be verified as the size of the nanoparticles produced was dependent on the ratio of silver atoms to capping agent molecules during synthesis.

Differences were not seen in the growth rates between control samples and bone cement loaded with antimicrobial nanoparticles (Table 2). However, a decrease in the slope of the growth curves is visible in Figure 6B; as pointed out by Perni et $\mathrm{al},{ }^{49}$ this is the consequence - that $\mu_{\max }$ is not the slope of the growth curve at the inflection point but is defined in the Baranyi model as the growth rate when the cell concentration tends to zero. Therefore, the action of such nanoparticles influences the behavior of the survivors. It seems that the lethality is caused by a single hit on the cells or through a cumulative effect (multiple hits) that cannot be fully recovered if cells survive.

The fluid in contact with the bone cement loaded with $\mathrm{Ag}$ nanoparticles contained $\mathrm{Ag}^{+}$ions that originated from the metal nanoparticles when silver dissolved in the solution (Figure 9). This dissolution phenomenon was faster at the beginning and carried on for at least 7 days; the observed pattern is typical of Fickian diffusion processes. The presence of $\mathrm{Ag}^{+}$ions in solution could, therefore, indicate that the function of the metal nanoparticles is to act as a reservoir of silver ions whose antimicrobial properties are well known. However, this does not appear to be the only mechanism of action, because the highest concentration of the smaller nanoparticles did not have antimicrobial activity although it gave the highest amount of silver ion release. This is in contrast with the results presented by Xiu et al, ${ }^{50}$ who claimed that if nanoparticles are prevented from releasing 
ions (using anaerobic conditions), they are harmless to bacteria. The different types of nanoparticles used in this work (tiopronin capped), compared to that in the work of Xiu et al (PEG and PVP coated), can account for the possible different outcomes.

A great deal is known about the damage inflicted on microorganisms by Ag nanoparticles, which can result in bacterial inactivation (cell membrane, ${ }^{51,52}$ enzymes ${ }^{53}$ ); however, as pointed out by $\mathrm{Xu}$ et $\mathrm{al},{ }^{54}$ it is still not well known what is actually causing the bacteria death. The presence of oxygen has been recently proved to be essential for Ag nanoparticles to induce cell death through the production of reactive oxygen species (ROS), ${ }^{54,55}$ whose lethality is well known. It appears, therefore, that Ag nanoparticles can lead to microbial inactivation, providing $\mathrm{Ag}^{+}$ions that are capable of interfering with enzymes interacting with the sulfur in the protein chains and by generating ROS. From this point of view, the use of Ag nanoparticles would be superior to the use of $\mathrm{Ag}^{+}$ions in providing antimicrobial properties to bone cement. Moreover, environmental factors such as the presence of anions $\left(\mathrm{Cl}^{-}, \mathrm{SO}_{4}{ }^{2-}\right)$ and ligands (cysteine) have also been implicated in the reduction of $\mathrm{Ag}^{+}$ions antimicrobial activity, ${ }^{56}$ providing further support for the use of nanoparticles instead of their salt precursor. Another benefit made available by nanoparticles is the possibility of binding other compounds (for example, osteintegrative molecules) to the capping agent, obtaining nanomaterials with dual action.

Ultimately, the shift in balance between Ag nanoparticles and salts will be determined not only by the properties of such compounds but also by other considerations such as economical and environmental costs of production. It is foreseeable that synthetic routes employing 'green conditions' (low temperature and no hazardous chemicals or physical agents such UV radiations) would be necessary to favor the use of nanoparticles over Ag salts. The route to obtained nanoparticles presented in this work is in line with this view as room temperature conditions are used and the reagents do not present significant hazard.

No influence of the Ag nanoparticles, for both types and at any concentration tested, was found on cytotoxicity (Figure 7) and compression strength of bone cement (Figure 8). Thus, bone cement impregnated with Ag nanoparticles capped with tiopronin is employable as it has the same properties of the control, and additionally, exhibits antimicrobial activity. Hence, no 'trade off' is necessary between antimicrobial properties and both mechanical and cytotoxicity characteristics.

\section{Conclusion}

The exceptional stability of the tiopronin-stabilized particles results from the formation of strong Ag-S bonds at the head of the molecule, hydrogen bonding between the chains of parallel attached molecules, and charge-charge repulsion between de-protonated carboxylic acid end groups. This stability enables the particles to be reliably isolated as a solid, stored for long periods, and re-dispersed without affecting their size. This ease of handling and compatibility with biological systems makes the silver-tiopronin particles especially suitable for producing nanoparticles for incorporation into bone cement. Particles synthesized with a higher ratio of stabilizing agent tiopronin to silver were smaller and contained a larger organic fraction than those synthesized with less tiopronin to silver.

When incorporated in bone cement, the smaller nanoparticles did not have antimicrobial activity, whilst the bigger ones were capable of reducing the contamination of MRSA at concentrations as low as $0.1 \%$. The antimicrobial activity increased with increasing amount of nanoparticles encapsulated in bone cement. Even at the highest concentration tested $(1 \%)$, no negative effect on the mechanical properties or on the cytotoxicity of the bone cement was detected. The nanoparticles in the bone cement released $\mathrm{Ag}^{+}$ions when immersed in fluid but this was not the reason for the antimicrobial activity seen.

Our work shows that it is possible to prepare bone cement with antimicrobial activity using Ag nanoparticles without relying on antibiotics, and therefore, reducing the risk of inducing resistance in bacteria.

\section{Acknowledgments}

Polina Prokopovich would like to acknowledge Arthritis Research UK (ARUK:18461) for funding this study. Ralph Leech is funded by Sigma Aldrich Fine Chemicals (SAFC) Hitech and the Engineering and Physical Sciences Research Council (EPSRC).

\section{Disclosure}

Authors disclose no conflicts of interest in this work.

\section{References}

1. Agency for Healthcare Research and Quality (AHRQ News and Numbers) RMU. Orthopedic Procedures Increase Dramatically in Seven Years [press release]. Rockville, MD: Agency for Healthcare Research and Quality; 2007 [July 18]. Available from: http://archive.ahrq.gov/ news/nn/nn071807.htm. Accessed May 15, 2013.

2. National Joint Registry for England and Wales. 7th Annual Report. 2010. Available from: http://www.njrcentre.org.uk/njrcentre/portals/0/njr\%20 7th\%20annual\%20report\%202010.pdf. Accessed May 15, 2013. 
3. Kuster MS, Stachowiak GW. Factors affecting polyethylene wear in total knee arthroplasty. Orthopedics. 2002;25(Suppl 25):S235-S242.

4. Birrell F, Johnell O, Silman A. Projecting the need for hip replacement over the next three decades: influence of changing demography and threshold for surgery. Ann Rheum Dis. 1999;58:569-572.

5. Zimmerli W, Trampuz A, Ochsner PE. Prosthetic-joint infections. N Engl J Med. 2004;351:1645-1654.

6. Trampuz A, Zimmerli W. Prosthetic joint infections: update in diagnosis and treatment. Swiss Medl Wkly. 2005;135:243-251.

7. Darouiche RO. Treatment of infections associated with surgical implants. N Engl J Med. 2004;350:1422-1429.

8. Prokuski L, Clyburn TA, Evans RP, Moucha CS. Prophylactic antibiotics in orthopaedic surgery. Instr Course Lect. 2011;60:545-555.

9. Meehan J, Jamali AA, Nguyen H. Prophylactic antibiotics in hip and knee arthroplasty. J Bone Joint Surg Am. 2009;91:2480-2490.

10. Tyllianakis ME, Karageorgos AC, Marangos MN, Saridis AG, Lambiris EE. Antibiotic prophylaxis in primary hip and knee arthroplasty comparison between cefuroxime and two specific antistaphylococcal agents. J Arthroplasty. 2010;25:1078-1082.

11. Nowinski RJ, Gillespie RJ, Shishani Y, Cohen B, Walch G, Gobezie R. Antibiotic-loaded bone cement reduces deep infection rates for primary reverse total shoulder arthroplasty: a retrospective, cohort study of 501 shoulders. J Shoulder Elbow Surg. 2012;21:324-328.

12. Kaplan L, Kurdziel M, Baker KC, Verner J. Characterization of daptomycin-loaded antibiotic cement. Orthopedics. 2012;35:E503-E509.

13. Ofluoglu EA, Bulent E, Derya AM, et al. Efficiency of antibiotic-loaded polymethylmethacrylate rods for treatment of the implant-related infections in rat spine. $J$ Spinal Disord Tech. 2012;25:E48-E52.

14. Kazemzadeh-Narbat M, Noordin S, Masri BA, et al. Drug release and bone growth studies of antimicrobial peptide-loaded calcium phosphate coating on titanium. J Biomed Mater Res Part B Appl Biomater. 2012;100:1344-1352.

15. Tan H, Guo S, Yang S, Xu X, Tang T. Physical characterization and osteogenic activity of the quaternized chitosan-loaded PMMA bone cement. Acta Biomater. 2012;8:2166-2174.

16. Kittinger C, Marth E, Windhager R, et al. Antimicrobial activity of gentamicin palmitate against high concentrations of Staphylococcus aureus. J Mater Sci Mater Med. 2011;22:1447-1453.

17. Montanaro L, Speziale P, Campoccia D, et al. Scenery of Staphylococcus implant infections in orthopedics. Future Microbiol. 2011;6: 1329-1349

18. Perni S, Prokopovich P, Parkin IP, Wilson M, Pratten J. Prevention of biofilm accumulation on a light-activated antimicrobial catheter material. J Mater Chem. 2010;20:8668-8673.

19. Perni S, Piccirillo C, Pratten J, et al. The antimicrobial properties of light-activated polymers containing methylene blue and gold nanoparticles. Biomaterials. 2009;30:89-93.

20. Perni S, Prokopovich P, Piccirillo C, Pratten J, Parkin IP, Wilson M. Toluidine blue-containing polymers exhibit potent bactericidal activity when irradiated with red laser light. J Mater Chem. 2009;19:2715-2723.

21. Perni S, Shama G, Kong M. Cold atmospheric plasma disinfection of cut fruit surfaces contaminated with migrating microorganisms. J Food Prot. 2008;71:1619-1625.

22. Perni S, Liu DW, Shama G, Kong MG. Cold atmospheric plasma decontamination of the pericarps of fruit. J Food Prot. 2008;71:302-308.

23. Perni S, Shama G, Hobman J, et al. Probing bactericidal mechanisms induced by cold atmospheric plasmas with Escherichia coli mutants. Appl Phys Lett. 2007;90(7):073902.

24. Perni S, Prokopovich P, Pratten J, Parkin IP, Wilson M. Nanoparticles: their potential use in antibacterial photodynamic therapy. Photochem Photobiol Sci. 2011;10:712-720.

25. Pathak SP, Gopal K. Evaluation of bactericidal efficacy of silver ions on Escherichia coli for drinking water disinfection. Environ Sci Pollut Res Int. 2012;19:2285-2290.

26. Ewald A, Hösel D, Patel S, Grover LM, Barralet JE, Gbureck U. Silver-doped calcium phosphate cements with antimicrobial activity. Acta Biomater. 2011;7:4064-4070.
27. Buckley JJ, Lee AF, Olivi L, Wilson K. Hydroxyapatite supported antibacterial Ag3PO4 nanoparticles. J Mater Chem. 2010;20:8056-8063.

28. Leaper DJ. Silver dressings: their role in wound management. Int Wound J. 2006;3:282-294.

29. Pratten J, Nazhat SN, Blaker JJ, Boccaccini AR. In vitro attachment of Staphylococcus epidermidis to surgical sutures with and without Agcontaining bioactive glass coating. J Biomater Appl. 2004;19:47-57.

30. Freeman AI, Halladay LJ, Cripps P. The effect of silver impregnation of surgical scrub suits on surface bacterial contamination. Vet $J$. 2012;192:489-493.

31. Pollini M, Paladini F, Catalano M, et al. Antibacterial coatings on haemodialysis catheters by photochemical deposition of silver nanoparticles. J Mater Sci Mater Med. 2011;22:2005-2012.

32. Turkevich J, Stevenson PC, Hillier J. A study of the nucleation and growth processes in the synthesis of colloidal gold. Discuss Faraday Soc. 1951;11:55-75.

33. Jana D, De G. Spontaneous generation and shape conversion of silver nanoparticles in alumina sol, and shaped silver nanoparticle incorporated alumina films. J Mater Chem. 2011;21:6072-6078.

34. Vasilev K, Sah VR, Goreham RV, Ndi C, Short RD, Griesser HJ. Antibacterial surfaces by adsorptive binding of polyvinyl-sulphonatestabilized silver nanoparticles. Nanotechnology. 2010;21:215102.

35. Deng Y, Sun Y, Wang P, et al. Nonlinear optical properties of silver colloidal solution by in situ synthesis technique. Curr Appl Phys. 2008;8:13-17.

36. Panacek A, Kvitek L, Prucek R, et al. Silver colloid nanoparticles: synthesis, characterization, and their antibacterial activity. $J$ Phys Chem B. 2006;110:16248-16253.

37. Le AT, Tam LT, Tam PD, et al. Synthesis of oleic acid-stabilized silver nanoparticles and analysis of their antibacterial activity. Mater Sci Eng C. 2010;30:910-916.

38. Henglein A, Giersig M. Formation of colloidal silver nanoparticles: capping action of citrate. J Phys Chemy B. 1999;103:9533-9539.

39. Stevanovic M, Kovacevic B, Petkovic J, Filipic M, Uskokovic D. Effect of poly-alpha, gamma, L-glutamic acid as a capping agent on morphology and oxidative stress-dependent toxicity of silver nanoparticles. Int J Nanomed. 2011;6:2837-2847.

40. Le Guevel X, Spies C, Daum N, Jung G, Schneider M. Highly fluorescent silver nanoclusters stabilized by glutathione: a promising fluorescent label for bioimaging. Nano Res. 2012;5:379-387.

41. Gil-Tomas J, Tubby S, Parkin IP, et al. Lethal photosensitisation of Staphylococcus aureus using a toluidine blue O-tiopronin-gold nanoparticle conjugate. J Mater Chem. 2007;17:3739-3746.

42. Dong X, Ji X, Wu H, Zhao L, Li J, Yang W. Shape Control of Silver Nanoparticles by Stepwise Citrate Reduction. J Phys Chem C. 2009;113:6573-6576.

43. Bechert T, Steinrucke P, Guggenbichler JP. A new method for screening anti-infective biomaterials. Nat Med. 2000;6:1053-1056.

44. Templeton AC, Chen SW, Gross SM, Murray RW. Water-soluble, isolable gold clusters protected by tiopronin and coenzyme A monolayers. Langmuir. 1999;15:66-76.

45. Huang T, Murray RW. Luminescence of tiopronin monolayer-protected silver clusters changes to that of gold clusters upon galvanic core metal exchange. J Phys Chem B. 2003;107:7434-7440.

46. Leff DV, Ohara PC, Heath JR, Gelbart WM. Thermodynamic Control of Gold Nanocrystal Size: Experiment and Theory. J Phys Chem. 1995;99:7036-7041.

47. Gofberg I, Mandler D. Preparation and comparison between different thiol-protected Au nanoparticles. J Nanopart Res. 2010;12: $1807-1811$

48. Biesta-Peters EG, Reij MW, Joosten H, Gorris LGM, Zwietering MH. Comparison of two optical-density-based methods and a plate count method for estimation of growth parameters of Bacillus cereus. Appl Environ Microbiol. 2010;76:1399-1405.

49. Perni S, Andrew PW, Shama G. Estimating the maximum growth rate from microbial growth curves: definition is everything. Food Microbiol. $2005 ; 22: 491-495$ 
50. Xiu ZM, Zhang QB, Puppala HL, Colvin VL, Alvarez PJ. Negligible particle-specific antibacterial activity of silver nanoparticles. Nano Lett. 2012; 12:4271-4275.

51. Dror-Ehre A, Mamane H, Belenkova T, Markovich G, Adin A. Silver nanoparticle-E. coli colloidal interaction in water and effect on E. coli survival. J Colloid Interface Sci. 2009;339:521-526.

52. Li WR, Xie XB, Shi QS, Zeng HY, OU-Yang YS, Chen YB. Antibacterial activity and mechanism of silver nanoparticles on Escherichia coli. Appl Microbiol Biotechnol. 2010;85:1115-1122.

53. Shrivastava S, Bera T, Roy A, Singh G, Ramachanrarao P, Dash D. Characterization of enhanced antibacterial effects of novel silver nanoparticles. Nanotechnology. 2007;18:225103.
54. Xu H, Qu F, Xu H, et al. Role of reactive oxygen species in the antibacterial mechanism of silver nanoparticles on Escherichia coli O157:H7. Biometals. 2012;25:45-53.

55. Choi O, Hu ZQ. Size dependent and reactive oxygen species related nanosilver toxicity to nitrifying bacteria. Environ Sci Technol. 2008;42:4583-4588.

56. Xiu ZM, Ma J, Alvarez PJ. Differential effect of common ligands and molecular oxygen on antimicrobial activity of silver nanoparticles versus silver ions. Environ Sci Technol. 2011;45:9003-9008.
International Journal of Nanomedicine

\section{Publish your work in this journal}

The International Journal of Nanomedicine is an international, peerreviewed journal focusing on the application of nanotechnology in diagnostics, therapeutics, and drug delivery systems throughout the biomedical field. This journal is indexed on PubMed Central, MedLine, CAS, SciSearch $®$, Current Contents ${ } /$ Clinical Medicine,

\section{Dovepress}

Journal Citation Reports/Science Edition, EMBase, Scopus and the Elsevier Bibliographic databases. The manuscript management system is completely online and includes a very quick and fair peer-review system, which is all easy to use. Visit http://www.dovepress.com/ testimonials.php to read real quotes from published authors.

Submit your manuscript here: http://www.dovepress.com/international-journal-of-nanomedicine-journal 